\title{
Clinical observation of Pregnancy outcome in Teenage Pregnancy
}

\author{
Atima Bharti' ${ }^{1}$ Anubha Vidyarthi ${ }^{2}$ \\ ${ }^{I}$ Associate Professor Department of Obstetrics \& Gyanecology Rajendra Institute of Medical Science \\ Ranchi, Jharkhand \\ ${ }^{2}$ Associate Professor Department of Obstetrics \& Gyanecology Rajendra Institute of Medical Science \\ Ranchi, Jharkhand
}

\begin{abstract}
Aim: To evaluate outcome of pregnancy in teenage mothers.

Method: In this retrospective study we reviewed 120 teenage mothers in the age group 13 to 19 years from indoor and outdoor Department of Obstetrics \& Gynaecology. Marital status and gestational age was not under consideration.

Result: Maximum teenage mothers were in the age group of 18-19 years incidence being 65\%. Majority of them were married and illiterate. $37.5 \%$ had spontaneous term vaginal delivery, $14.16 \%$ had preterm vaginal delivery. 23.3\% had lower segment caesarean section, cephalopelvic disproportion was the indication in $10.83 \%$. Instrumental delivery in $1.66 \%$ of cases. Out of 72 babies delivered, $60 \%$ was of low birth weight (1500-2500gms). $9.16 \%$ was of very low birth weight $<1500 \mathrm{gms} .12 .5 \%$ was preterm dead babies.

Conclusion: Teenage pregnancy should be discouraged as it leads to increased maternal and perinatal morbidity and mortality. It can be prevented by proper sex education, literacy, use of contraceptives and proper antenatal care.
\end{abstract}

Keywords: Adolescent, Teenage pregnancy, Pregnancy outcome

\section{Introduction}

Teenage pregnancy also known as adolescent pregnancy occurs in almost every ethnic, social and economic group and is an universal phenomenon in all known cultures. Teenage pregnancy was defined as pregnancy occurring between the maternal ages 13-19 completed years at delivery. It has been estimated that about 16 million women aged 14-19 years give birth yearly worldwide, this is about $11 \%$ of total births. Majority (95\%) of those birth occurred in developing countries and 5\% only occurred in developed countries [1].Teenage pregnancy ranged from $2 \%$ in China to about $18 \%$ in Latin America and the Caribbean [2]. Birth rate of teenage women in developing countries can be up to 20 times higher than that in developed countries and these birth rates ranged from $1 \%$ in Japan to over $20 \%$ per annum in Congo [3]. According to UNICEF, worldwide every $5^{\text {th }}$ child is born to teenage mothers. The incidence of teenage pregnancies varies dramatically between the different countries. Approximately $90 \%$ of teenage birth occurring in developing countries [4]. Regardless of marital status, early childbirth is more dangerous for both young mother and her child as compared to older mothers. According to world health organization updated September 2014

- Complication during pregnancy and childbirth are the second cause of death for 15-19 years old girls globally.

- Every year, some 3 million girls aged 15 to 19 years undergo unsafe abortion.

- Babies born to adolescent mother face a substantially higher risk of dying than those born to women aged 20 to 24 years.

Adolescent pregnancy can also have negative social and economic effects on girls, their families and communities. Many girls who become pregnant have to drop out of school. Teenage mothers and their babies are at high risk of developing health problems such as obesity, eclampsia, anaemia and very preterm delivery [5]. Prevalence of low birth weight or very low birth weight is high in teenage mothers, this low birth weight may have adverse long term effect on babies health and developments [6]. Maternal mortality is nearly 5 times higher for teenage compared to older women [7].

\section{Materials And Methods}

Teenage pregnant girls (13-19 years of age) were randomly selected from indoor and outpatient department of Obstetrics \& Gynaecology, Rajendra Institute of Medical Sciences, Ranchi. Hundred and twenty patients were selected irrespective of marital status and gestational age. Informed consent was taken. Ethical clearance was taken from ethical Committee. Routine and special investigations were done. 3 level scan was done in first trimester, 22 weeks and 34 weeks. 
Outcome of pregnancy was noted under following headings:

- Nature of labour

- Duration of labour

- Mode of delivery

- Any complications occurring during pregnancy, labour and puerperium.

Perinatal outcome was assessed by noting down the following points:

- APGAR score

- Weight in Kilogram

- Gestational age

- Admission to neonatal intensive care unit (NICU)

- Stillbirth

- Early neonatal death

- Congenital malformation

\section{Obstetrical outcome $\mathbf{n}=120$ Table I}

\section{Result}

Table 1 (A)

\begin{tabular}{|l|l|l|}
\hline Pregnancy & Gestational Age & Percentage \\
\hline Term pregnancy & 37 weeks & $59.17 \%$ \\
\hline Preterm & $29-36$ weeks & $18.33 \%$ \\
\hline Very preterm & $<28$ weeks & $22.5 \%$. \\
\hline
\end{tabular}

Table $1(B)$

\begin{tabular}{|l|l|}
\hline During Pregnancy & Percentage \\
\hline Anaemia mild & $71 \%$ \\
\hline Anaemia moderate \& severe & $29 \%$ \\
\hline Preeclampsia & $7.5 \%$ \\
\hline Eclampsia & $5 \%$ \\
\hline Preterm prelabour rupture of membrane & $4.16 \%$ \\
\hline Antepartum Haemorrhage & $0.83 \%$ \\
\hline
\end{tabular}

Table I shows that only $59.17 \%$ of teenage mothers reached up to term while the rest had preterm and very preterm deliveries. $100 \%$ of patients had anaemia during pregnancy.

Mode of delivery Table II $\mathbf{n}=\mathbf{1 2 0}$

\begin{tabular}{|l|l|}
\hline Mode of Delivery & Percentage \\
\hline Spontaneous term vaginal delivery & $37.5 \%$ \\
\hline Preterm vaginal delivery & $14.16 \%$ \\
\hline Lower segment caesarean section & $23.3 \%$ \\
\hline Instrumental delivery & $1.66 \%$ \\
\hline Assisted breech delivery & $0.83 \%$ \\
\hline
\end{tabular}

Early termination of pregnancy table III $n=120$

\begin{tabular}{|l|l|}
\hline Mode of Delivery & Percentage \\
\hline Medical termination of pregnancy (MTP) & $11.6 \%$ \\
\hline Incomplete abortion & $8.3 \%$ \\
\hline Septic abortion & $<1 \%$ \\
\hline Molar pregnancy & $0.83 \%$ \\
\hline Ectopic pregnancy & $0.83 \%$ \\
\hline
\end{tabular}

Table II shows that only $37.5 \%$ of teenage mothers had spontaneous term vaginal delivery. Incidence of preterm vaginal delivery and lower segment cesarean section was $14.16 \%$ and $23.3 \%$ respectively. The commonest indication for cesarean section was cephalopelvic disproportion i.e. $10.8 \%$. Other indications were foetal distress and obstructed labour.

Perinatal outcome table IV $n=72$

\begin{tabular}{|l|l|l|l|}
\hline Perinatal Outcome & Gestational Age & Birth Weight & Percentage \\
\hline Term babies & $>37$ weeks & $2.5 \mathrm{~kg}$ & $6.6 \%$ \\
\hline Preterm babies & $29-36$ weeks & $1.5-2.49 \mathrm{~kg}$ & $60 \%$ \\
\hline Very preterm & $<28$ weeks & $<1.5 \mathrm{~kg}$ & $9.16 \%$ \\
\hline Alive & - & - & $61.66 \%$ \\
\hline
\end{tabular}


Clinical Observation Of Pregnancy Outcome In Teenage Pregnancy

\begin{tabular}{|l|l|l|l|}
\hline Perinatal death & - & - & $4.16 \%$ \\
\hline Still Birth & - & - & $3.3 \%$ \\
\hline Premature dead babies & - & - & $12.5 \%$ \\
\hline
\end{tabular}

Table IV shows $60 \%$ of babies were of low birth weight and only $6.6 \%$ of babies were of adequate weight i.e. $>2.5 \mathrm{~kg}$. Incidences of alive babies were low accounting to just $61.66 \%$.

\section{Discussion}

Early marriage is common in Jharkhand state. In our study $83.30 \%$ of teenage mothers were married and only $16.66 \%$ were unmarried. Young age at marriage is associated with early onset of sexual activity and fertility [8]. Teenage pregnancy is a global problem and is considered a high risk group inspite of conflicting evidence [9]. It is coming as one of the most important social and public health problems all over the world with a varying prevalence rate. In recent years the incidence is increasing due to early onset of puberty, early sexual activity in girls and relative lack of education on contraceptive methods. Although adolescent marriage is a cognizable offence in India it is still a common practice in many parts of the country. A high fertility rate social customs, poverty and ignorance make early marriage a common feature in this part of the world. The teenage period itself constitutes a high risk group requiring high priority services [10].

On study should a high prevalence of anaemia (100\%). Low iron stores along with insufficient dietary intake increases the risk of iron deficiency anaemia during pregnancy. Sarkar CS et al in 1991 in their study found anaemia in $76.6 \%$ of teenage pregnancy [11]. Various studies of conducted in different parts of the world revealed preterm delivery to be the most common complication as reported to the $10.56 \%$ by Dubashi SS [12], $13.2 \%$ by Sharma et al [13], 4.8\% by Mahajan S [14], 27.45\% by G Yasmin et al [15], 51.8\% by Abu- Heija Adel et al [1]. Our study had a similar prevalence $40.38 \%$. High prevalence of preterm and very preterm deliveries could be attributed to high rate of premature rupture of membranes among teenagers or immaturity of the uterine or cervical blood supply which may predispose teenage mothers to subclinical infection, and preterm delivery or psychological instability of young mothers [16, 17]. Most common indication of caesarean section in teenage mothers was cephalopelvic disproportion followed by foetal distress [18]. Our study showed similar result. Biological immaturity in teenage mothers itself is an inherent risk factor for poor outcome and even adequate perinatal care does not completely eliminate the risk [19].

In India and other developing countries maternal mortality among teenage mothers were high because of unsafe abortion. In most developed countries including USA 30-60\% adolescent pregnancy end in abortion [20]. In Ethiopia Kwast et al [21] reported a maternal mortality rate of 12.7/1000 in mothers 15-19 years of age. $50 \%$ of them due to unsafe abortion compared to 3.6/1000 in mother aged 25-29 years.

It is estimated that 70,000 female teenagers die each year because they are pregnant before they are physically mature enough for successful motherhood [22]. In Nigeria Harrison et al [23] reported increased rate of maternal mortality in young pregnant girls $<15$ years of age (maternal mortality $27 / 1000$ compared to 4/1000 in women 20-24 years).

\section{Conclusion}

WHO published guidelines in 2011 with the UN population fund (UNFPA) on preventing early pregnancies and reducing poor reproductive outcome. These made recommendation for action that countries could take, with 6 main objectives.

- Reducing marriage before the age of 18.

- Creating understanding and support to reduce pregnancy before the age of 20.

- Increasing the use of contraception by adolescents at risk of unintended pregnancy.

- Reducing coerced sex among adolescent.

- Reducing unsafe abortion among adolescents.

- Increasing use of skilled antenatal childbirth and postnatal care among adolescents.

Adverse outcomes can be a ameliorated by free and compulsory education for the girl child, making contraceptives available to teen, especially emergency contraceptives, quality antenatal care and provision of essential obstetric care.

\section{Bibliography}

[1]. Abu-Heij Adel, Al Haddabi R, Al Bash Majeda, Al Mahaihsi Nadia et al. Early Teenage pregnancy: Is it safe? The journal of Obstetrics and Gynaecology of India (March-April 2016) 66 (2): 88-92.

[2]. Keller T, Morgan A, Gnerreiro et al. International and HBSC study group. Addressing the socioeconomic determinants of adolescent health: experiences from the WHO/HBSC Forum 2007. Drt J public health. 2009; 54: 278-84.

[3]. Alouni S, Randriambololona D, Randriamboavonjy R. Risk factors of teenage pregnancies, deliveries and postpartum in the departmement of Loinet. J Gynecol Obstet Biol Reprod (Paris). 2014; 4:168-9. 
[4]. PUNKD, Chanha M outcome of adolescent pregnancy at Kathmandu University Hospital, Kathmandu univ Med J 2011; 33 (1): 503.

[5]. Huang CC, Lin YC, Huang YT et al. Comparison of medical issues in antenatal and perinatal periods in early youth, adolescent and young adult mothers in Taiwan, a 10 years nationwide study, BMC pregnancy childbirth. 2014; 14: 260-3.

[6]. Paranjothy S, Broughton S, Adappa R et al. Teenage pregnancy: Who suffers? Arch Dis child. 2009; 94: 239-45.

[7]. Craine N, Midgley C, Zon L et al. Elevated teenage conception risk amongst looked after children; a national audit. Public health. 2014; 128: 668-70.

[8]. Debras E, Revaux A, Bricon et al. Obstetric and neonatal outcomes of adolescent pregnancy: a Cohort study in a hospital in Scine Saint Denis France. Gynecol Obstet Fertil. 2014; 42: 579-84.

[9]. Mahavarkar SH, Madhu CK, Nule VD. A comparative study of Teenage pregnancy J Obstet Gynecol. 2008 Aug; 28 (6): 604.

[10]. A Kumar, Tej Singh, Suparna Basu et al. Indian J Pediatrics 2007 14 (10): 927-931.

[11]. Sarkar CS, Giri AK, Sarkar B. Outcome of teenage pregnancy and labour: a retrospective study, J Indian Med Ass 1991; 89: 197199.

[12]. Dubashi SS, Wani R. Teenage pregnancy Bombay Hospital Journal 2008; 50 (2): 236-239.

[13]. Sharma AK, Chabra P, Gupta P, Aggarwal P et al. Pregnancy in adolescents. A community based study. Indian journal of Preventive and Social Medicine. 2003; 34 (1): 24-32.

[14]. Mahajan S. Teenage deliveries and risk of adverse outcome. A hospital based case-control study; UNFPA, Secretariat of the pacific community 2007.

[15]. Ghazla Yasmin, Aruna Kumar, Bharti Parihar. "Teenage pregnancy- Its impact on maternal and foetal outcome". International Journal of scientific study. 2014; 1 (6): 9-13.

[16]. Shuaib A, Frass K, Al-Hazariet et al. Pregnancy outcomes of mothers aged 17 years or less. Saudi Med J. 2011; 32: 166-70.

[17]. Haldre K, Rahu K, Rahu M et al. Individual and familial factors associated with teenage pregnancy: an interview study. Eur J public health 2009; 19: 266-70.

[18]. Soubhagya Talwar, Venkatesh G IOSR JDMS Vol 6 issue 6 May-June 2013. Pg 81-83.

[19]. Scholl TO, Hediger, ML, Salmon RN et al. Association between low gynaecological age and preterm birth. Paediats Perinat Epidemiol 1989; 3:357-366.

[20]. Adolescent pregnancy. Issues in adolescent health and development. WHO discussion paper on adolescence WHO 2004, 986.

[21]. Kwast BE, Rochat RW, Kidane-Mariam, Maternal mortality in Addis-Ababa Ethiopia, studies in family planning 1986; 17: 288301.

[22]. Mayor S, Pregnancy and childbirth are leading cause of teenage girls in developing countries BMJ $2004 ; 328: 1152$.

[23]. Harrison KA. The influence of maternal and parity on child bearing with special reference to primigravidae aged 15 years and under. Br J Obstet Gynecol 1985; (Suppl 5): 23-31. 